\title{
Micronutrient Deficiency in Severe Preeclampsia
}

\author{
Selina Akhtar ${ }^{1}$, Taskina Ali², Shelina Begum³ ${ }^{3}$,Sultana Ferdousi ${ }^{4}$
}

\begin{abstract}
Background: Micronutrient such as calcium, magnesium and zinc deficiency are associated with preeclampsia. Objective: To observe serum calcium, magnesium and zinc levels in severe preeclamptic women. Methods: This cross sectional study was carried out in the Department of Physiology, Bangabandhu Sheikh Mujib Medical University, Shahbag, Dhaka from July 2009 to June 2010. 60 cases of preeclampsia, aged 18-39 years and $>20$ th weeks of pregnancy were included in the study group. They were further sub divided into group $\mathrm{B}_{1}$ (30 mild preeclampsia) and group $\mathrm{B}_{2}$ ( 30 severe preeclampsia). Age and gestational period matched 30 normotensive pregnant women (Group A) were also studied as control. All the preeclamptic women were selected from the Obstetric and Gynaecology in and out patient Department of BSMMU and Dhaka Medical College Hospital. Serum calcium and magnesium was measured by colorimetric and serum zinc was measured by spectrophotometric method. For statistical analysis one way ANOVA, independent sample t test and $\div^{2}$ test were used. Results: The mean serum calcium, magnesium and zinc levels were significantly $(\mathrm{p}<0.001)$ lower in both group of preeclampsia than normotensive pregnant women. Again serum calcium and zinc levels were significantly lower $(\mathrm{P}<0.05)$ in severe preeclampsia compared to mild preeclampsia whereas serum magnesium levels were found almost similar in both group of preeclampsia ( $\mathrm{P}>0.05$ ). Again in this study, $40 \%$ mild, $73.3 \%$ severe preeclamptic women and $20 \%$ normotensive pregnant women had hypocalcaemia. $36.7 \%$ mild, $30.0 \%$ severe preeclamptic women and 3.3\% normotensive pregnant women had hypomagnesaemia and $6.7 \%$ mild, $20 \%$ severe preeclamptic women and no normotensive pregnant women had hypozincemia. Conclusion: This study may conclude that micronutrient deficiency may be one of the risk factor of preeclampsia and increases the risk of its severity. Therefore early detection and supplementation to treat this deficiency may reduce the incidence of preeclampsia.
\end{abstract}

Key words: Calcium, magnesium, zinc, preeclamptic women.

\footnotetext{
J Bangladesh Soc Physiol. 2013 June; 8(1): 26-32 For Authors Affiliation, see end of text.

http://www.banglajol.info/index.php/JBSP
}

\section{Introduction}

$\mathbf{P}$ reeclampsia is termed as the triad of hypertension to the extent of $140 / 90 \mathrm{~mm}$ $\mathrm{Hg}$ or more with proteinuria and with or without edema in pregnant women who were previously normotensive and non-proteinuric ${ }^{2}$.

Received April 2011; $\quad$ Accepted November 2011
It is a clinical state imposing multi system disorder involving placenta, liver, kidney, blood, neurological and cardiovascular systems giving rise to clusters of symptoms usually appear at 20th weeks of pregnancy ${ }^{1}$

Preeclampsia occurs in about $6 \%$ of all pregnancies. The incidence varies with geographic location. ${ }^{3,4}$. It is also believed to be

J Bangladesh Soc Physiol. 2013, June; 8(1): 26-32 
accountable to $15 \%$ of premature deliveries and $17.6 \%$ of world wide maternal death. The disease is mild in $75 \%$ of cases and severe in $25 \%$ of all cases of preeclampsia and $10 \%$ occur in pregnancies of less than 34 weeks gestation ${ }^{5}$.

Several groups of researchers reported an association between altered calcium, magnesium and zinc metabolism in preeclampsia and also emphasized the contribution of these micronutrient deficiencies in the etiology of the disease. It has been found common in developing countries due to their low dietary intake of essential minerals and vitamins ${ }^{6}$.

Preeclampsia is caused by multiple factors and elimination of any factor can reduce the mortality of mothers and infants ${ }^{7}$.

Some researchers observed significantly lower serum calcium level in preeclamptic women compared to normotensive pregnant women. They suggested that low serum calcium may cause high blood pressure by stimulating parathyroid hormone and renin release which in turn increase its intracellular level in vascular smooth muscle resulting in vasoconstriction $6,8,9$.

Magnesium is an essential trace element and an important cofactor of many enzyme system. It provides significant influence on vascular tonicity, and reactivity and thus involved in the physiological mechanism of blood pressure regulation. Low serum magnesium levels are associated with preeclampsia because of its relationship with impaired antioxidant activity which results in increased blood pressure and dietary deficiency of this elements ${ }^{6}$.

On the basis of therapeutic effects and the known vasodilating properties of magnesium, it was suggested that a deficiency in magnesium contributed to the development of preeclampsia ${ }^{10}$ as significantly lower serum magnesium levels in preeclamptic women was observed by various studies $6,8,9$.

Among the essential trace elements zinc has an illustrative role in enhancing reproductive health and required for optimal cellular function working with more than 300 different enzymes ${ }^{11}$.It has been reported that $82 \%$ of the pregnant women worldwide are likely to have inadequate dietary intake of zinc and physiological alterations in zinc concentration have been found related to preeclampsia $^{12,13}$.

Significantly lower serum zinc level in preeclamptic women compared to healthy pregnant women and increased risk of zinc deficiency in women of low socioeconomic status have been reported by various studies. 1,6, 13, 14 .

Literature survey showed that attempts have been made to explore the link between the changes in levels of serum calcium, magnesium and zinc in pregnant women and high blood pressure $^{6}$.

In Bangladesh about $16 \%$ of maternal deaths are caused by preeclampsia and Eclampsia ${ }^{15}$. Micronutrients levels were studied by several investigators of other countries. Varying results were obtained in these different investigations in different countries. But most of these are in conclusive and conflicting. In addition, very few studies examined the relationship between severity of this condition and micronutrient deficiency. Therefore this study was undertaken to observe the serum calcium, magnesium and zinc levels in Bangladeshi preeclamptic women to find out the possible role of these micronutrients deficiency in preeclampsia as well as relationship of this deficiency with severity of this clinical condition.

\section{Methods}

The present cross sectional study was carried out in the Department of Physiology, BSMMU, Dhaka between July 2009 to June 2010 and the protocol of this study involving human subject was approved by the central ethical review committee of BSMMU.Serum calcium, magnesium and zinc levels 60 pregnant women of preeclampsia, age ranged from 18-39 years, $>20$ th weeks of pregnancy were assessed. On 
the basis of BP and proteinuria ${ }^{6}$ they were further divided into group $\mathrm{B}_{1}$ consisting of 30 mild preeclamptic women(DBP£100 $\mathrm{mm}$ of $\mathrm{Hg}$, mild edema, proteinuria + ) and group $\mathrm{B}_{2}$ consisting of 30 severe preeclamptic women(DBP£110 mm of $\mathrm{Hg}$, mild, moderate to severe odema and proteinuria,,+++++++++$)$. For comparison age and gestational period matched 30 normotensive pregnant women control (group A) were also studied. Both control and preeclamptic patients were selected from Obstetric and Gynae in and out patient Department of BSMMU and Dhaka Medical College Hospital. Subjects with history of Diabetes mellitus, renal, cardiovascular, liver disease, chronic hypertension, endocrine disorder, any chronic illness, Hydatidiform mole, Malignancy, Hemophilia were excluded from the study. After selection of the subjects, the purpose of the study was explained to each subject. When they agreed for participation, then an informed written consent was taken. Detailed family and medical history were taken. Thorough clinical examinations were done and Systolic and Diastolic blood pressure were carefully recorded. Information about edema and proteinuria were collected from patients clinical record. Then $5 \mathrm{ml}$ of venous blood was collected from ante-cubital vein under aseptic precaution from each subject and serum was prepared for biochemical tests. Serum calcium and magnesium was determined by colorimetric method and serum zinc was measured by Spectrophotometric method. Data were expressed as Mean $+\mathrm{SD}$. Data analysis was done with SPSS version-12. For statistical analysis one way ANOVA, independent sample t test and $\div^{2}$ test were performed.

\section{Results}

In this study, all the groups were matched for age and gestational period but the mean BMI, SBP and DBP were significantly higher in group $\mathrm{B}_{1}$ and $\mathrm{B}_{2}(\mathrm{p}<0.001)$ than that of group A. Again this value was significantly higher in $B_{2}$ than those of $\mathrm{B}_{1}$ (Table-I).

Table I: Age, BMI, Gestational period, SBP \& DBP in different groups of subjects ( $\mathrm{n}=90)$.

\begin{tabular}{lccccc}
\hline Groups & $\begin{array}{c}\text { Age }(\mathrm{yrs}) \\
\left(\mathrm{kg} / \mathrm{m}^{2}\right)\end{array}$ & $\begin{array}{c}\text { BMI } \\
(\text { weeks })\end{array}$ & $\begin{array}{c}\text { Ges.Period } \\
(\mathrm{mm} \text { of Hg })\end{array}$ & $\begin{array}{c}\text { SBP } \\
(\mathrm{mm} \text { of Hg })\end{array}$ & DBP \\
\hline $\mathbf{A}(\mathrm{n}=30)$ & $25.13 \pm 4.97$ & $23.22+1.88$ & $31 \pm 4.39$ & $108.17+8.95$ & $68.67 \pm 8.19$ \\
$\mathrm{~B}_{1}(\mathrm{n}=30)$ & $24.63+5.70$ & $25.05 \pm 2.13$ & $32.67 \pm .64$ & $144.33+6.79$ & $94.50 \pm 4.01$ \\
$\mathrm{~B}_{2}(\mathrm{n}=30)$ & $25.60+5.70$ & $26.63 \pm 2.50$ & $32.03 \pm .45$ & $166.67+10.28$ & $113.17 \pm 5.79$ \\
\hline
\end{tabular}

Statistical Analysis

\begin{tabular}{llllll}
\hline Groups & \multicolumn{5}{c}{ p value } \\
\hline A vs B ${ }_{1}$ vs $B_{2}$ & $0.787^{\text {ns }}$ & $0.000^{* * *}$ & $0.237^{\text {ns }}$ & $0.000^{* * *}$ & $0.000^{* * *}$ \\
$\mathrm{~A}$ vs $B_{1}$ & $0.680^{\text {ns }}$ & $0.001^{* * *}$ & $0.115^{\text {ns }}$ & $0.000^{* * *}$ & $0.000^{* * *}$ \\
$\mathrm{~A}$ vs $B_{2}$ & $0.771^{\text {ns }}$ & $0.000^{* * *}$ & $0.295^{\text {ns }}$ & $0.000^{* * *}$ & $0.000^{* * *}$ \\
$\mathrm{~B}_{1}$ vs $B_{2}$ & $0.514^{\text {ns }}$ & $0.01^{* *}$ & $0.510^{\text {ns }}$ & $0.000^{* * *}$ & $0.000^{* * *}$ \\
\hline
\end{tabular}

Data are expressed as Mean $\pm \mathrm{SD}$. Statistical analysis was done by one-way ANOVA and independent sample $t$ test. $\mathrm{SBP}=$ Systolic blood pressure, $\mathrm{DBP}=$ Diastolic blood pressure Group $\mathrm{A}=$ Normotensive pregnant women (control), Group $\mathrm{B}_{1}=$ Mild preeclamptic women, Group $\mathrm{B}_{2}=$ Severe preeclamptic women.
$* * *=\mathrm{p}<0.001$
$\mathrm{ns}=$ Non significant
$* *=\mathrm{p}<0.01$
$\mathrm{n}=$ Number of subjects 
Mean serum calcium, magnesium and zinc level were significantly $(\mathrm{p}<0.001)$ lower in both the study groups $\mathrm{B}_{1}$ and $\mathrm{B}_{2}$ in comparison to that of control group A. Again serum calcium and zinc levels were significantly lower $(\mathrm{P}<0.05)$ in group $\mathrm{B}_{2}$ in comparison to that of group $\mathrm{B}_{1}$. But serum magnesium levels were almost similar in group $\mathrm{B}_{1}$ and $\mathrm{B}_{2}(\mathrm{P}>0.05)$. (Table-III).

Again in this study $40 \%$ mild, $73.3 \%$ severe preeclamptic women and $20 \%$ normotensive pregnant women had Hypocalcaemia, 36.7\% mild, $30.0 \%$ severe preeclamptic women and 3.3\% normotensive pregnant women had hypomagnesaemia and $6.7 \%$ mild, $20 \%$ severe preeclamptic women and $0 \%$ normotensive pregnant women had hypozincemia (Table III). Significantly higher frequency of hypocalcemia was observed in severe preeclampsia compared to mild preeclampsia and normotensive pregnant women Similar results in hypozincemia and hypomagnesemia were found in severe preeclampsia

Table II: Serum calcium, magnesium and zinc levels in different groups $(\mathrm{n}=90)$

\begin{tabular}{|c|c|c|c|}
\hline Groups & Serum calcium (mg/dl) & Serum magnesium (mg/dl) & Serum zinc $(\mu \mathrm{gm} / \mathrm{l})$ \\
\hline $\bar{A}$ & $9.09 \pm 0.83$ & $2.04 \pm 0.27$ & $1153.33 \pm 167.09$ \\
\hline $\mathrm{B}_{1}$ & $8.42 \pm 0.68$ & $1.7 \pm 0.12$ & $950 \pm 143.83$ \\
\hline $\mathrm{B}_{2}$ & $7.96 \pm 0.69$ & $1.72 \pm 0.25$ & $855 \pm 157.75$ \\
\hline \multicolumn{4}{|c|}{ Statistical Analysis: } \\
\hline Groups & & $\mathrm{p}$ value & \\
\hline$A$ vs $B_{1}$ vs $B_{2}$ & $0.000^{* * *}$ & $0.000^{* * *}$ & $0.000^{* * *}$ \\
\hline $\mathrm{A}$ vs $\mathrm{B}_{1}$ & $0.001^{* *}$ & $0.000^{* * *}$ & $0.000^{* * *}$ \\
\hline$A$ vs $B_{2}$ & $0.000^{* * *}$ & $0.000^{* * *}$ & $0.000^{* * *}$ \\
\hline $\mathrm{B}_{1}$ vs $\mathrm{B}_{2}$ & $0.01^{* *}$ & $0.647^{\mathrm{ns}}$ & $0.01^{*}$ \\
\hline
\end{tabular}

Data are expressed as Mean \pm SD. Statistical analysis was done by one-way ANOVA and independent sample $t$ test. Group $\mathrm{A}=$ Normotensive pregnant women(control), Group $\mathrm{B}_{1}=$ Mild preeclamptic women.

Group $\mathrm{B}_{2}=$ Severe preeclamptic women.

$* * *=\mathrm{p}<0.001, * *=\mathrm{p}<0.01, \mathrm{~ns}=$ Non significant, $\mathrm{n}=$ Number of subjects

Table III: Frequency of the subjects by hypocalecmia, hypomagnesium hypozincemia in different groups $(n=90)$.

\begin{tabular}{lccc}
\hline Group & Hypocalcaemia No (\%) & Hypomagnesaemia No $(\%)$ & Hypozincemia No (\%) \\
\hline A & $6(20 \%)$ & $1(3.3 \%)$ & $0(0 \%)$ \\
B1 & $12(40 \%)$ & $11(36.7 \%)$ & $2(6.7 \% 0$ \\
B2 & $22(73.3 \%)$ & $9(30 \%)$ & $6(20 \%)$ \\
\hline \multicolumn{2}{l}{ Statistical analysis: } & & \\
\hline \multicolumn{2}{l}{ Groups } & p value & $0.492^{\mathrm{ns}}$ \\
\hline A vs B & $0.158^{\mathrm{ns}}$ & $0.002^{* *}$ & $0.02^{*}$ \\
$\mathrm{~A}$ vs B & $0.000^{* * *}$ & $0.01^{*}$ & $0.254^{\mathrm{ns}}$ \\
$\mathrm{B}_{1}$ vs $\mathrm{B}_{2}$ & $0.01^{*}$ & $0.785^{\mathrm{ns}}$ &
\end{tabular}

Data are expressed as number of subjects. For statistical analysis, $\div^{2}$ test.

Group $\mathrm{A}=$ Normotensive pregnant women(control), Group $\mathrm{B}_{1}=$ Mild preeclamptic women

Group $\mathrm{B}_{2}=$ Severe preeclamptic women

$*=\mathrm{p}<0.05, * *=\mathrm{p}<0.01, \mathrm{~ns}=$ Not significant, $\mathrm{n}=$ Number of subjects

J Bangladesh Soc Physiol. 2013, June; 8(1): 26-32 


\section{Discussion}

The present study assessed the serum calcium, magnesium and zinc level in preeclamptic women to find out their status in mild and severe stages of this clinical problem. In addition the frequency distribution of the hypocalcemia, hypomagnesaemia and hypozincemia in different stages of preeclamptic and normotensive pregnant women were also studied.

The result of this study showed significantly lower serum calcium, magnesium and zinc level in all cases of preeclampsia than control. Similar types of findings were reported by various published article and also published in our previous report. 6, 8,16-20,21. Again in this study, significantly lower calcium and zinc levels in severe preeclamptic women than those of mild cases of preeclampsia also agree to the results of similar comparison in several published reports $6,7,9$. But in case of serum magnesium, no statistically significant difference was observed between two preeclamptic groups. This is also similar to the findings observed by some rsearcher ${ }^{6}$.

Results of the present study showed that significant number of preeclamptic cases were suffering from deficiency of this three trace elements.Moreover,the deficiency were more pronounced in severe preeclampsia specially regarding calcium and zinc. This observation suggests that calcium and zinc deficiency deteriorates more with severity of this clinical problem. On further analysis, this study showed that there was marked mild calcium deficiency but almost no deficiency of zinc and magnesium was found in normotensive pregnants.

Various studies addressed this problem to find out the relationship between micronutrient deficiency and preeclampsia.They focused the relationship between deficiency of micronutrients and risk of preeclampsia.Nutritional status of the preeclamptic women,onset or progress of the disease and their nutritional deficiency has been implicated in the development of this disorder. It has been also cited that preeclampsia is more common in poor women. In addition nutrient can modulate oxidative stress by increasing or decreasing free radicals or antioxidants or by providing substrate for the formation of free radicals 22.23

The Physiological effect of calcium ion on smooth muscle cell contractility is well known. Low serum calcium in pregnancy stimulates release of parathyroid hormone and renin which in turn increases intracellular calcium in vascular smooth muscle. This increased smooth muscle calcium causes vasoconstriction and thereby increased vascular resistance leading to rise in blood pressure in preeclamptic mother 6, 8,9,24.

Decreased level of magnesium during pregnancy might increase the vasoconstrictor response of a large number of neurohormonal agents including epinephrine, norepinephrine, angiotensin II, serotonin and bradykinin leading to rise in blood pressure ${ }^{6}$. Moreover, some other investigators suggested that, endothelial dysfunction and the consequent vasospasm also acts as contributory factor in the pathogenesis of preeclampsia. Deficient concentration of magnesium can not stimulate release of the endothelial vasodilator prostacycline and therefore causes vasoconstriction, 25,26 .

Various possible explanations were proposed by different investigators to explore the link between nutritional deficiency and preeclampsia. Under increased oxidative stress, ongoing excessive lipid peroxidation, endothelial dysfunction, vasospasm which results from the imbalance of vasodilators and vasoconstrictors in these micronutrient deficient environments may act as contributory factor for preeclamptic pregnancy $1,6,8,13$.

Increased load of oxidative stress or excessive lipid peroxidation may act as an attributing factor in the pathogenesis of preeclampsia. Magnesium and zinc is required for the proper functioning of antioxidant enzymes which protect free radicals injury. Deficiency these elements may withdraw the effect of antioxidant potential of cells leading to free radical injury and increased blood pressure ${ }^{1,6,13}$.

From the above discussion it is obvious that the increased frequency of micronutrient deficient pregnants in preeclampsia has underscored the role of micronutrient deficiency in the 
pathogenesis of preeclampsia. In addition the magnitude of deficiency is related to the severity of preeclamtic state as suggested by the present result.

In the present study, most of the women are from poor socioeconomic status and their dietary intake of calcium, magnesium and zinc rich food was inadequate. Though the natural trend of homeostatic mechanism tend to maintain specially calcium, magnesium and zinc level to near normal but the sustained presence of lower level of serum calcium, magnesium and zinc in preeclamptic women may indicate the chronicity of micronutrient deficiency which may be a causative factor for the occurrence of this disease in this group of pre eclamptic women.

\section{Conclusion}

So, the present results concluded these micronutrient deficiency may be the possible contributors in etiology of preeclampsia. Therefore routine screening and close surveillance of these micronutrients during antenatal period is needed in pregnant women for appropriate nutritional replacement which may reduce the incidences of preeclampsia.

\section{Acknowledgement}

The authors of this study acknowledge the financial assistance from the research grant provided by the University Grants Commission of Bangladesh.

\section{Author Affiliations}

*1. Selina Akhtar, Assistant professor, Department of Physiology, Z. H Sikder Women's Medical College, Dhaka. Email: selina.tuba@gmail.com.

2. Taskina Ali, Associate professor, Department of Physiology, Bangabandhu Sheikh Mujib Medical University, Dhaka Bangladesh.Email: taskinadr@gmail.com

3. Shelina Begum, Chairman, Department of Physiology, Bangabandhu Sheikh Mujib Medical University,Dhaka Bangladesh.Email:shelina1982 @gmail.com

4. Sultana Ferdousi. Associate professor, Department of Physiology, Bangabandhu Sheikh Mujib Medical University, Dhaka Bangladesh.Email: sferdousiratna @gmail.com

* For correspondence

J Bangladesh Soc Physiol. 2013, June; 8(1): 26-32

\section{References}

1. Ashraf M, Nasarullah M, Salam A, Khurshid R, Ahmed Z. Maternal serum zinc concentration in gravidae suffering from preeclampsia. A.P.M.C. 2007; 1(1): 24-27.

2. Idogun ES, Imarengiaye CO, Momob SM. Extracellular calcium and magnesium in preeclampsia and Eclampsia. Afr J of Reprod Health. 2007; 11(2): 89- 94 .

3. Witlin AG, Sibai B. Hypertension in pregnancy: Current concepts of preeclampsia. Annu rev of med.1997; 48 (1): 115-127.

4. Reynolds C, Mabie WC, Sibai BM. Preeclampsia. [Internet] 2010, [Cited 2010, December 7] Abailable from http://www. health. am/pregnancy/ preeclampsia/

5. Lim KH, Steinberg G. Preeclampsia. [Internet] 2009, July31 [Cited 2010 May 23]. Abailable from http:// emedicine.medscape.com/article/1476919overview.

6. Jain S. Sharma P, Kulshreshtha S, Mohan G, Singh $\mathrm{S}$. The role of serum calcium, magnesium, and zinc in preeclampsia. Biol Trace elem Res. 2010; 133(2): $162-70$.

7. Bahadoran P, Zendehdel. The relationship between serum zinc and preeclampsia in health centers of Isfahan city in 2007. IJNMR.2010; 15(3): 1-5.

8. Sukonpan K, Phupong V. Serum calcium and serum magnesium in normal and preeclamptic pregnancy. Arch Gynecol Obstet.2005; 273: 12-16.

9. Punthumapol C. Kittichotpanich B. Serum calcium, magnesium and uric acid in pre- eclampsia and normal pregnancy. J. Med Assoc Thai. 2008; 91(7): 968-73.

10. Kisters K, Barenbrock M, Louwen F, Hausberg M, Rahn KH, Kosch M. Membrane, intracellular and plasma magnesium and calcium concentrations in preeclampsia. Am J hypertens. 2000; 13: 765-69.

11. Bader AA, Hussain T, Mosawi MA, Otaibi M, Abul H, Khalifa D, Dashti H. Serum zinc and copper concentrations in pregnant women from Kuwait. J. Trace Elem. Exp. Med. 1997; 10: 209-15.

12. Pathak P, Kapoor SK, Kapil U, Dwivedi SN. Serum magnesium level among pregnant women in a rural community of Haryana state. India. Eur. J. Clin. Nutr. 2003; 57: 1504- 06.

13. Nourmohamm-adi I, Akbaryan A, Fatemi Sh, Meamarzadeh AR Nourmohammadi . Serum zinc concentration in Iranian preeclamptic and normotensive pregnant women. Middle East J. Fam. Med. 2008; 6(4): 30-32. 
14. Kocak I, Mir A D, Uston C, Cengiz R. L. Does zinc deficiency have a role in pregnancy induced hypertension? T Klin jmcknl chsi.1999; 9: 18-21.

15. Rashid KM, Rahman M and Hayder S. 2004. Textbook of community medicine and public health, $4^{\text {th }}$ edition, $155 \mathrm{p}$.

16. Kanchapan S, Phupong V. Serum calcium and magnesium in normal and preeclamptic pregnancy.Arch Gynecol Obstet.2005;273:12-16

17. Kumru S, Aydin S, Simsek M, Sahin K, Yaman M, Ay G. Comparison of serum copper, zinc, calcium and magnesium levels in preeclamptic and healthy pregnant. Biol Trace elem Res. 2003; 94: 105 12.

18. Malas NO, Shurideh ZM. Does serum calcium in preeclampsia and normal pregnancy differ? Saudi Med J. 2001; 22 (10): 868-71

19. Akinloye O, Oyewale OJ, Oguntibeju OO. Evaluation of trace elements in pregnant women with preeclampsia. Afr. J. Biotechnol.2010; 9(32):5196-02.

20. Vahidrodsari F, Ayaty S, Tourabizadeh A, AyatAllahi H, Esmaeli H, Shahabian M. Serum calcium and magnesium in preeclamptic and normal pregnancies. A comparative study. J Reprod Fertil. 2008; 9 (3): 1-3.

21. Akhtar S,begum S,Ferdousi S.calcium and zinc deficiency in preeclamptic women. J Bangladesh soc physiol.2011;6(2):94

22. Odigie IP, Anortu RI, Adesiyun AE, Odum CU. Serum magnesium levels in non-pregnant, pregnant and preeclamptic women in Lagos, Nigeria. NigerianQuarterly journal of hospital medicine. 2004; 14:1-2.

23. Vasiljevic N, Vasiljevic M, Plecas D. The role of nutritional factors in preeclampsia and eclampsia. Srp Arh Celok Lek. 1996; 124(5-6): 156-59.

24. Roberts JM, Balk JL, Bodner LM, Belizan JM, Berge E, Martinez A. Nutrient involvement in preeclampsia.2003; J Nutr; 133(55): 1684-92.

25. Ritchie LD, King JC. Dietary calcium and pregnancy induced hypertension: is there a relation? Am J Clin Nutr. 2000; 71(50:1371-74.

26. Roberts JM, Magnesium for preeclampsia and Eclampsia. N. Engl. J. Med. 1995; 333(4): 250-51.

27. Laurant P, Touyz RM. Physiological and pathological role of magnesium in the cardiovascular system: implication in hypertension. J Hupertens; 18(9): 1177- 91. 